\title{
POTENCIAL FISIOLÓGICO DE SEMENTES DE SOJA DESSECADAS COM DIQUAT E PARAQUAT ${ }^{1}$
}

\section{PHYSIOLOGICAL POTENTIAL FOR DESSICATED SOYBEAN SEED WITH DIQUAT AND PARAQUAT}

\author{
Claudinei KAPPES ${ }^{2}$ \\ Marco Antônio Camillo de CARVALHO ${ }^{3}$ \\ Oscar Mitsuo YAMASHITA ${ }^{4}$
}

\begin{abstract}
RESUMO
O tipo, modo de ação e época em que o dessecante é aplicado na cultura da soja, são fatores que podem afetar a qualidade fisiológica das sementes. Porém, se a aplicação for realizada de maneira adequada, poderá ocorrer antecipação da colheita em alguns dias, obtendo sementes de maior qualidade. Assim, o presente trabalho teve como objetivo verificar o efeito da dessecação em pré-colheita no desempenho fisiológico de sementes de soja. O delineamento experimental foi de blocos ao acaso em esquema fatorial $3 \times 4$ (dessecantes $x$ épocas) com quatro repetições. Os dessecantes foram Diquat e Paraquat, ambos na dose de $400 \mathrm{~g}$ i.a. ha ${ }^{-1},+$ testemunha (sem dessecação). As épocas de aplicação foram nos estádios R6.0, R7.1, R7.2 e R7.3. As sementes foram submetidas ao teste de germinação, primeira contagem da germinação, índice de velocidade de germinação, envelhecimento acelerado, teste de frio e condutividade elétrica. Todos os testes foram realizados no Laboratório de Análise e Tecnologia de Sementes da Universidade do Estado de Mato Grosso. A análise de variância foi realizada, sendo os dessecantes comparados pelo teste de Tukey $(p<0,05)$. Apesar de terem proporcionado antecipação da colheita em apenas dois dias em relação à testemunha, a época mais favorável à dessecação, tanto com Diquat quanto Paraquat, é no estádio R7.3, sendo que os lotes dessecados com Paraquat apresentou melhor desempenho em alguns dos testes de qualidade avaliados.
\end{abstract}

Palavras-chave: Glycine max (L.) Merrill; dessecantes; germinação; vigor.

\begin{abstract}
The type, mode of action and time when the desiccant is applied on soybean, are factors that can affect the physiological quality seeds. But if the operation is performed adequately, it may occur in anticipation of the harvest a few days, getting seeds of higher quality. This work aimed at evaluating the desiccant effect of pre-harvest in the physiological performance of soybean seed. The design was blocks at randomized in a factorial $3 \times 4$ (desiccants $\times$ time) with four replications. The desiccants were Diquat and Paraquat, both in the dose of 400 g.i.a. ha ${ }^{-1},+$ control (without desicantion). The times of application were in stages R6.0, R7.1, R7.2 and R7.3. Seeds were subjected to fermenation test, first count of germination, the germination speed rate, accelerated aging, cold testing and electrical conductivity. All tests were carried out at analysis seed laboratory analysis and technology of the University of the State of Mato Grosso. The desiccants were compared by Tukey $(p<0.05)$. In spite of have provided anticipation of crop in only two days in relation to the control, the most favorable time to disecation, so much with Diquat as Paraquat, is at the stage R7.3, and disecateds lots with Paraquat presented better performance in some of the appraised quality tests.
\end{abstract}

Key-words: Glycine max (L.) Merrill; desiccants; germination; vigor.

\footnotetext{
1 Trabalho desenvolvido no município de Santa Carmem, MT - Brasil, safra 2006/2007.

${ }^{2}$ Engenheiro Agrônomo. Estrada Augusta, Chácara Sol Nascente, $n^{\circ} 31-A, 78545-000$, Santa Carmem, MT, Brasil. Universidade do Estado do Mato Grosso (UNEMAT). E-mail: code.agro@hotmail.com.

${ }^{3}$ Engenheiro Agrônomo, Doutor em Agronomia, Coordenador do Campus Universitário de Alta Floresta, MT, Universidade do Estado do Mato Grosso, Brasil. E-mail: marcocarvalho@unemat.br.

${ }^{4}$ Engenheiro Agrônomo, Mestre, Professor Assistente do Departamento de Agronomia, Universidade do Estado do Mato Grosso, Brasil. E-mail: yama@unemat.br.
} 


\section{INTRODUÇÃO}

Uma das etapas mais importantes na produção de soja é a obtenção de sementes de alta qualidade para serem utilizadas pelos agricultores no estabelecimento de suas lavouras (Rocha et al., 1984). Dentre os fatores que afetam o potencial fisiológico e sanitário das sementes de soja, destacam-se o momento da colheita e as condições do ambiente durante o período que as sementes permanecem no campo. Em vários trabalhos de pesquisa foi enfatizada a perda da qualidade das sementes quando as mesmas ficaram expostas às condições adversas de umidade relativa e temperatura do ambiente, durante o processo de maturação, após o ponto de maturidade fisiológica e também no período de pré-colheita (Lacerda et al., 2005). Os efeitos na qualidade fisiológica das sementes geralmente são traduzidos pelo decréscimo de germinação, no aumento de plântulas anormais e por redução no vigor de plântulas (Smiderle \& Cícero, 1998).

O controle de qualidade de sementes da soja é de fundamental importância na sua cadeia produtiva, caracterizando a colheita como importante etapa do processo (EMBRAPA, 2003). Com o atraso da colheita, associado à variação da umidade relativa do ar, tem-se alternância de ganho e perda de água das sementes, o que acarreta vários prejuízos como o aumento de rachadura e enrugamento do tegumento, acelerando, dessa forma, o processo de deterioração, em virtude de maior facilidade de penetração de patógenos e maior exposição do tecido embrionário ao ambiente (Zito, 1994).

Delouche (1980) considerou crítico o intervalo entre a maturidade fisiológica e a colheita. Assim, é importante que a colheita das sementes seja realizada o mais próximo possível do ponto de maturidade fisiológica, quando o teor de água variar entre 200 e $250 \mathrm{~g} \mathrm{~kg}^{-1}$. Quando colhida nessa fase, a planta ainda se encontra com uma quantidade relativamente grande de folhas e ramos verdes e úmidos, o que dificulta o uso de colhedoras, além de favorecer a maior ocorrência de injúria mecânica, devido ao elevado teor de água das sementes (Carvalho \& Nakagawa, 2000).

O uso de dessecantes pode-se constituir em alternativa para superação desses problemas por promover a secagem e queda das folhas, além de fazer com que as sementes percam água rapidamente, possibilitando a realização da colheita em período mais próximo ao ponto de maturidade fisiológica (Lacerda et al., 2005). Para Inoue et al. (2003) é uma alternativa empregada para minimizar a deterioração da qualidade das sementes.

Com a aplicação de dessecantes em uma lavoura de soja, ocorreu a antecipação da colheita em nove dias em relação à época usual, havendo redução no teor de água das sementes de 300 para $170 \mathrm{~g} \mathrm{~kg}^{-1}$, no período de três a cinco dias após aplicação (Costa, 1984), Em dois anos de pesquisa, esse autor verificou que, quando foi aplicado o dessecante Paraquat, obteve superioridade significativa na qualidade das sementes, mas no segundo ano não houve benefício acentuado para a germinação e o vigor. Nakashima et al. (2000) observaram que a aplicação de Paraquat pode ser feita já no estádio R6.5, sem redução significativa na produção, obtendo-se sementes com elevada qualidade fisiológica, o que permitiu a antecipação da colheita dos cultivares Savana e Doko em 11 e sete dias, respectivamente. Por outro lado, alguns dessecantes podem deixar resíduos, causando redução do vigor das sementes (Whigan \& Stoller, 1979).

Dessa forma, dependendo da maneira com que essa prática é realizada (tipo, modo de ação e época em que o dessecante é aplicado), a qualidade das sementes pode ser afetada, inviabilizando sua utilização tanto para sementes quanto para grãos. Contudo, se a aplicação for realizada de maneira adequada, poderá haver maior uniformidade da maturidade fisiológica da lavoura, antecipar a colheita em alguns dias e ainda obter sementes de maior qualidade fisiológica e sanitária (Lacerda et al., 2001; 2005).

Com base no exposto, o objetivo desse trabalho foi verificar o efeito dos dessecantes Diquat e Paraquat, aplicados em diferentes épocas, a fim de permitir a colheita antecipada de sementes de soja com o máximo potencial fisiológico.

\section{MATERIALE MÉTODOS}

O experimento foi conduzido em Latossolo Vermelho-Amarelo Distrófico (LVAd) (EMBRAPA, 2006), no ano agrícola de 2006/07, na área de campo comercial do Sítio Ivani, município de Santa Carmem, MT, situada à $12^{\circ} 00^{\prime} 15^{\prime \prime} \mathrm{S}$ e $55^{\circ} 14^{\prime} 21^{\prime \prime} \mathrm{W}$ Gr., com altitude de $365 \mathrm{~m}$. O clima predominante da região, segundo classificação de Koppen, é do tipo Aw, com precipitação e temperatura média anual de 2.500 $\mathrm{mm}$ e $24^{\circ} \mathrm{C}$, respectivamente. O cultivar (Glycine max L. Merrill) utilizado foi o M-SOY 8866, de ciclo médio (Monsanto, 2004), devido a sua adaptação e cultivo na região. As sementes foram tratadas, por ocasião da semeadura, com fungicida Carbendazin + Thiram, inseticida Fipronil e inoculante líquido com estirpes de Bradyrhizobium japonicum. A semeadura mecânica foi realizada no dia 09 de outubro de 2006, distribuindo 12 sementes por metro linear. A emergência das plântulas ocorreu aos seis dias após a semeadura (DAS) e a população final estabelecida foi de 220.000 plantas ha $^{-1}$. Para a adubação de base foram aplicados 313 $\mathrm{kg} \mathrm{ha}^{-1}$ da formulação $\mathrm{N}-\mathrm{P}_{2} \mathrm{O}_{5}-\mathrm{K}_{2} \mathrm{O}$ 00:25:25 $(0,04 \%$ de $\mathrm{B}, 0,2 \%$ de $\mathrm{Mn}$ e $0,3 \%$ de $\mathrm{Zn}$ ). Para o controle de plantas invasoras, insetos pragas e doenças foram utilizados produtos específicos para cada caso, seguindo recomendações técnicas da FundaçãoMT (2005).

Os tratamentos foram dispostos no delineamento blocos ao acaso em esquema fatorial $3 \times 4$ (dessecantes x épocas), com quatro repetições. Os dessecantes utilizados foram Diquat $(1,1$ 'etileno-2,2-bipiridilium íon) e Paraquat (1,1'-dimetil- 
4,4-bipiridilium íon), ambos na dose de $400 \mathrm{~g}$ i.a. ha $^{-1}$ (correspondente a $2 \mathrm{dm}^{3}$ ha $^{-1}$ dos produtos comerciais Reglone ${ }^{\circledR}$ e Gramaxone $^{\circledR}$, respectivamente) + testemunha (sem aplicação de dessecante). As épocas de aplicação foram no estádio R6.0, R7.1, R7.2 e R7.3, determinados pela escala fenológica de Ritchie et al. (1994), o que correspondeu aos 50, 57, 64 e 71 dias após o florescimento, respectivamente, ressaltando que a fase reprodutiva (R1- início da floração) foi aos 50 DAS. A dessecação foi realizada sempre no período da manhã, utilizando pulverizador costal manual, com capacidade de pressão de trabalho de 0,6 MPa, equipado com uma ponta do tipo jato cone vazio, calibrado para aplicar $200 \mathrm{dm}^{3} \mathrm{ha}^{-1}$ de calda, conforme recomendação especificada no rótulo dos dessecantes. Cada parcela experimental teve uma área total de $20 \mathrm{~m}^{2}$, contando com oito linhas de $5 \mathrm{~m}$ de comprimento e espaçadas de $0,50 \mathrm{~m}$ entre si. Para evitar danos mecânicos às sementes, foram coletadas manualmente aproximadamente 800 sementes no interior de cada parcela, quando estas estavam no estádio R9 (ponto de maturação de colheita), desprezando as extremidades. O teor de água das sementes no ato da colheita foi determinada através do método elétrico nãodestrutivo indireto, utilizando o aparelho modelo GAC 2100, marca Dickey-John ${ }^{\circledR}$.

A análise da qualidade das sementes foi realizada no Laboratório de Análise e Tecnologia de Sementes da Universidade do Estado de Mato Grosso (UNEMAT, Campus de Alta Floresta). As sementes não receberam qualquer tipo de tratamento para a realização dos testes. O potencial fisiológico das sementes foi avaliado pelos seguintes testes: a) germinação: realizado com quatro sub-amostras de 50 sementes para cada tratamento, a $25{ }^{\circ} \mathrm{C}$, em substrato de papel toalha tipo Germitest, na forma de rolo. O papel foi umedecido com volume de água destilada equivalente a 2,5 vezes a sua massa. As contagens foram efetuadas aos cinco e oito dias após a instalação, e os resultados expressos em porcentagem de plântulas normais, conforme instruções das Regras para Análise de Sementes RAS (Brasil, 1992); b) primeira contagem de germinação: avaliado conjuntamente com o teste de germinação, computando-se o número de plântulas normais obtidas no quinto dia após a instalação do teste, com os resultados expressos em porcentagem de plântulas normais; c) índice de velocidade de germinação (IVG): também avaliado de forma conjunta com teste de germinação, conforme as recomendações das RAS (Brasil, 1992). O cálculo do IVG foi feito segundo a metodologia proposta por Maguire (1962); d) envelhecimento acelerado: realizado com quatro sub-amostras de 50 sementes para cada tratamento, as sementes foram distribuídas sobre telas de alumínio, fixadas no interior de caixas plásticas $(11,0 \times 11,0 \times 3,0 \mathrm{~cm})$, nas quais foram adicionados $40 \mathrm{~cm}^{3}$ de água. As caixas foram tampadas e mantidas em câmara de germinação (BOD), regulada a temperatura constante de $42^{\circ} \mathrm{C}$, permanecendo por $48 \mathrm{~h}$ (AOSA, 1983). Posteriormente as sementes foram submetidas ao teste de germinação (BRASIL, 1992) com as avaliações realizadas no quinto dia, computandose a porcentagem de plântulas normais; e) teste de frio: realizado com quatro sub-amostras de 50 sementes por tratamento, as quais foram distribuídas em papel Germitest previamente umedecido, da mesma maneira como efetuado para o teste de germinação. Os rolos foram colocados no interior de sacos plásticos $(18,0 \times 25,0 \times 10,0 \mathrm{~cm})$ e mantidos em câmara fria regulada a $10^{\circ} \mathrm{C}$, durante sete dias. Após esse período, foram transferidos para o germinador a $25{ }^{\circ} \mathrm{C}$, onde permaneceram por cinco dias, quando então realizaram-se as contagens das plântulas normais (Brasil, 1992); f) condutividade elétrica: realizada pelo sistema "bulk", segundo metodologia proposta pelo Comitê de Vigor da AOSA (1983), utilizando quatro subamostras de 50 sementes por tratamento, as quais foram pesadas em balança de precisão, colocadas em copos plásticos contendo $75 \mathrm{~cm}^{3}$ de água destilada. Os copos foram mantidos em germinador, por $24 \mathrm{~h}$ a $25^{\circ} \mathrm{C}$. Após esse período, as sementes foram agitadas suavemente e feitas as leituras da solução de embebição das sementes com condutivímetro Delta OHM - modelo HD 8706-R1. Posteriormente, foram calculadas as condutividades elétricas das soluções de embebição, com os valores expressos em $u S \mathrm{~cm}^{-1} \mathrm{~g}^{-1}$ de sementes.

Os resultados foram submetidos à análise de variância, sendo as médias dos tratamentos comparadas pelo teste de Tukey $(p<0,05)$. O aplicativo computacional utilizado foi o Sistema de Análise Estatística - SANEST (Zonta \& Machado, 1987).

\section{RESULTADOS E DISCUSSÃO}

Para todas as épocas, tanto a aplicação de Diquat quanto a de Paraquat, provocou a dessecação rápida das folhas, proporcionando uma redução no ciclo da cultura (Tabela 1), quando comparada com a testemunha. Não foi constatada diferença no ciclo da cultura quando comparado os dessecantes dentro de cada época, sendo que as sementes das plantas dessecadas pelos dois produtos foram colhidas no mesmo dia (estádio R9). O teor de água das sementes foi semelhante para todos os tratamentos, em função das condições climáticas ocorridas e pelo fato de serem colhidos no mesmo estádio de desenvolvimento.

Para todos os testes houve interações significativas $(p<0,01)$ para os fatores avaliados. $O$ efeito dessas interações, através do desdobramento dos dessecantes dentro de cada época de aplicação, tendo suas médias comparadas pelo teste de Tukey $(p<0,05)$ está apresentado na Tabela 2. 
KAPPES, C. et al. Potencial fisiológico de sementes de soja...

TABELA 1 - Ciclo da cultura e teor de água das sementes de soja, por ocasião do ponto de maturação de colheita, em função da dessecação com Diquat e Paraquat em diferentes épocas. Sítio Ivani, Santa Carmem, MT, 2006/07.

\begin{tabular}{ccccc}
\hline & \multicolumn{4}{c}{ Ciclo da cultura (DAS $\left.{ }^{1}\right)$} \\
\hline \multirow{2}{*}{ Dessecante } & \multicolumn{4}{c}{ Época de aplicação } \\
\cline { 2 - 5 } & $\mathrm{R} 6.0$ & $\mathrm{R} 7.1$ & $\mathrm{R} 7.2$ & $\mathrm{R} 7.3$ \\
\hline Diquat & 113 & 117 & 121 & 125 \\
Paraquat & 113 & 117 & 121 & 125 \\
Testemunha & 127 & 127 & 127 & 127 \\
\hline \multicolumn{5}{c}{ Teor de água das sementes $\left(\mathrm{g} \mathrm{kg}^{-1}\right)$} \\
\hline Diquat & $\mathrm{R} 6.0$ & $\mathrm{R} 7.1$ & $\mathrm{R} 7.2$ & $\mathrm{R} 7.3$ \\
Paraquat & 172,5 & 174,6 & 180,8 & 168,4 \\
Testemunha & 171,5 & 177,8 & 185,2 & 172,2 \\
\hline
\end{tabular}

TABELA 2 - Resultados de germinação (G), primeira contagem de germinação (PCG), índice de velocidade de germinação (IVG), envelhecimento acelerado (EA), teste de frio (TF) e condutividade elétrica (CE) das sementes de soja em função da dessecação com Diquat e Paraquat em diferentes épocas. Sítio Ivani, Santa Carmem, MT, 2006/07.

\begin{tabular}{|c|c|c|c|c|}
\hline \multicolumn{5}{|c|}{ G (\% de plântulas normais) } \\
\hline \multirow{2}{*}{ Dessecante } & \multicolumn{4}{|c|}{ Época de aplicação } \\
\hline & R6.0 & R7.1 & R7.2 & R7.3 \\
\hline Diquat & $26,5 \mathrm{~b}$ & $25,0 \mathrm{~b}$ & $47,5 \mathrm{~b}$ & $81,0 \mathrm{a}$ \\
\hline Paraquat & $27,5 \mathrm{~b}$ & $28,5 \mathrm{~b}$ & $54,5 \mathrm{~b}$ & 87,5 a \\
\hline Testemunha & $78,5 \mathrm{a}$ & $76,0 \mathrm{a}$ & $83,5 \mathrm{a}$ & $84,0 \mathrm{a}$ \\
\hline \multicolumn{5}{|c|}{ PCG (\% de plântulas normais) } \\
\hline & R6.0 & R7.1 & R7.2 & R7.3 \\
\hline Diquat & $21,0 \mathrm{~b}$ & $22,5 \mathrm{~b}$ & $40,0 \mathrm{~b}$ & $68,5 \mathrm{a}$ \\
\hline Paraquat & $16,0 \mathrm{~b}$ & $23,0 \mathrm{~b}$ & $48,0 \mathrm{~b}$ & 80,5 a \\
\hline Testemunha & 70,5 a & $67,0 \mathrm{a}$ & $77,5 \mathrm{a}$ & $77,5 \mathrm{a}$ \\
\hline \multicolumn{5}{|c|}{ IVG } \\
\hline & R6.0 & R7.1 & R7.2 & R7.3 \\
\hline Diquat & $2,4 \mathrm{~b}$ & $2,4 \mathrm{~b}$ & $4,4 \mathrm{~b}$ & $7,5 \mathrm{a}$ \\
\hline Paraquat & $2,6 \mathrm{~b}$ & $2,7 \mathrm{~b}$ & $5,2 b$ & $8,5 \mathrm{a}$ \\
\hline Testemunha & $7,5 \mathrm{a}$ & $7,3 \mathrm{a}$ & $8,1 \mathrm{a}$ & $8,2 \mathrm{a}$ \\
\hline \multicolumn{5}{|c|}{ EA (\% de plântulas normais) } \\
\hline & R6.0 & R7.1 & R7.2 & R7.3 \\
\hline Diquat & $17,5 \mathrm{~b}$ & $20,0 \mathrm{~b}$ & $21,0 \mathrm{c}$ & $68,0 \mathrm{~b}$ \\
\hline Paraquat & $20,0 \mathrm{~b}$ & $14,0 \mathrm{~b}$ & $41,5 \mathrm{~b}$ & 85,0 a \\
\hline Testemunha & $73,0 \mathrm{a}$ & 80,5 a & 83,0 a & $77,5 \mathrm{ab}$ \\
\hline \multicolumn{5}{|c|}{ TF (\% de plântulas normais) } \\
\hline & R6.0 & R7.1 & R7.2 & R7.3 \\
\hline Diquat & $33,0 \mathrm{~b}$ & $28,5 \mathrm{~b}$ & $53,5 \mathrm{~b}$ & $55,0 \mathrm{~b}$ \\
\hline Paraquat & $32,5 \mathrm{~b}$ & $24,0 \mathrm{~b}$ & $46,5 \mathrm{~b}$ & 71,0 a \\
\hline Testemunha & $64,5 \mathrm{a}$ & $70,0 \mathrm{a}$ & 76,5 a & 70,5 a \\
\hline \multicolumn{5}{|c|}{$\mathrm{CE}\left(\mu \mathrm{S} \mathrm{cm} \mathrm{c}^{-1} \mathrm{~g}^{-1}\right)$} \\
\hline & R6.0 & R7.1 & R7.2 & R7.3 \\
\hline Diquat & $317,7 \mathrm{c}$ & $300,1 \mathrm{~b}$ & $188,8 \mathrm{~b}$ & $126,3 \mathrm{a}$ \\
\hline Paraquat & $264,8 \mathrm{~b}$ & $258,9 b$ & $178,2 b$ & $131,5 \mathrm{a}$ \\
\hline Testemunha & $144,2 \mathrm{a}$ & $121,9 \mathrm{a}$ & $119,1 \mathrm{a}$ & $129,7 \mathrm{a}$ \\
\hline
\end{tabular}

Médias seguidas com mesma letra na coluna não diferem entre si pelo teste de Tukey $(p<0,05)$.

No teste de germinação foi verificado que as testemunhas apresentaram os maiores percentuais quando comparadas com as plantas dessecadas nos estádios R6.0, R7.1 e R7.2. mostrando que a dessecação nessas fases provoca prejuízos para a germinação das sementes (Tabela 2). Os efeitos prejudiciais da dessecação em relação ao poder germinativo das sementes também já foram estudados por Baur et al. (1977). Em virtude da maturidade fisiológica atingida pelas sementes, a dessecação no estádio R7.3, aos 71 dias após o florescimento, foi a melhor época para tal prática, independentemente do dessecante aplicado, mantendo-se dentro do padrão nacional de 
germinação, que é de $80 \%$ (Brasil, 2005). Segundo Carvalho et al. (1978), na cultura da soja, o melhor resultado quanto à germinação das sementes foi obtido com a aplicação de dessecantes aos 75 dias após o florescimento, isto é, quando as sementes já tinham atingido a sua maturidade fisiológica, estando em conformidade com os resultados aqui obtidos. Pode-se inferir que, a dessecação realizada no estádio R7.3 promoveu aumento na germinação das sementes, concordando com Lacerda et al. (2005), ao mencionarem que quando a aplicação é efetuada de maneira adequada, pode resultar na obtenção de sementes de maior qualidade fisiológica. Pesquisas realizadas confirmam que a técnica da dessecação não diminui a germinação e que, pelo contrário, usando a dessecação, o poder germinativo é incrementado. Testes conduzidos no Brasil mostraram que a porcentagem de germinação de sementes das plantas não dessecadas foi menor quando comparada com tratadas (Roman et al., 2001).

Quanto a primeira contagem de germinação e o índice de velocidade de germinação (Tabela 2), o desempenho das sementes foi semelhante ao verificado para o teste de germinação, ressalvandose que esses testes são relacionados entre si. A maioria das sementes originou plântulas normais aos cinco dias de implantação do teste e o atraso na dessecação proporcionou maiores percentuais de germinação. As plantas testemunha e as dessecadas no estádio R7.3 tiveram sementes com um alto vigor, estando em conformidade com os resultados obtidos por Andreoli (1977), que observou maior vigor nas sementes de plantas dessecadas logo após estas terem atingido a maturidade fisiológica. Porém, discorda dos obtidos por Durigan \& Carvalho (1980), que não observaram diferença significativa na velocidade de germinação das sementes de soja dessecadas com Paraquat em diferentes épocas.

Para o envelhecimento acelerado (Tabela 2) foi observado que as sementes das testemunhas originaram os maiores percentuais de plântulas normais, diferindo das plantas dessecadas nos estádios R6.0, R7.1 e R7.2, sendo justificado pela imaturidade fisiológica das sementes por ocasião das aplicações. Na dessecação efetuada no estádio R7.3, os maiores percentuais de germinação foram obtidos para os tratamentos com o Paraquat e a testemunha. Resultados semelhantes foram conseguidos por Durigan (1979), que ao avaliar a aplicação de Paraquat em alguns cultivares de soja, concluiu que a aplicação não prejudicou a qualidade das sementes. A dessecação com Diquat proporcionou os menores percentuais de germinação após envelhecimento acelerado nos estádios R7.2 e R7.3. De modo geral, as plântulas normais apresentaram-se semelhantes às obtidas no teste de germinação para a testemunha, mostrando que não houve alteração da qualidade das sementes em função do estresse proporcionado por esse teste.

O teste de frio (Tabela 2) também apresentou resultados semelhantes aos constatados no teste germinação nos estádios R6.0, R7.1 e R7.2. Na dessecação realizada no estádio R7.3, as plantas dessecadas com Paraquat foram as que resultaram em sementes com os maiores percentuais de plântulas normais, igualando-se à testemunha, sendo superior estatisticamente em relação ao dessecante Diquat, confirmando os resultados obtidos por Durigan (1979) já referidos anteriormente. A aplicação de Diquat resultou no menor percentual nessa mesma época, concordando com Whigan \& Stoller (1979), ao mencionarem que alguns dessecantes podem causar redução no vigor das sementes. De modo geral, o teste de frio apresentou percentual de plântulas normais menor em relação aos testes de germinação e envelhecimento acelerado, sendo as sementes consideradas de baixa qualidade fisiológica, pois a capacidade de germinação de um lote de sementes, em condições de laboratório, deve ser superior a $80 \%$ para a obtenção de um bom estande no campo (Marcos Filho, 1980).

Nos resultados de condutividade elétrica (Tabela 2), foi possível verificar que as sementes oriundas das plantas dessecadas nos estádios R6.0, R7.1 e R7.2 foram as que apresentaram o menor vigor em relação à testemunha. Esses resultados discordam dos obtidos por Lacerda et al. (2005), que não constataram efeito significativo dos dessecantes, testemunha e épocas de aplicação na cultura da soja. As sementes das testemunhas e as das plantas dessecadas no estádio R7.3, tanto com Diquat quanto com Paraquat, foram as que apresentaram os menores valores de condutividade, porém, ainda são caracterizadas como de baixa qualidade fisiológica, conforme os valores sugeridos por Vieira (1994).

\section{CONCLUSÃO}

Os resultados obtidos permitiram concluir que:

- apesar de ter antecipado a colheita em apenas dois dias em relação à testemunha, a época mais favorável à dessecação, para os dois dessecantes, é o estádio R7.3, sendo que os lotes dessecados com Paraquat apresentou melhor desempenho em alguns dos testes de qualidade empregados.

\section{AGRADECIMENTOS}

Aos proprietários do Sítio Ivani, Armando Pedro Kappes e Nelson Roque Kappes e à Universidade do Estado de Mato Grosso - UNEMAT (Campus de Alta Floresta), pela oportunidade oferecida e possibilidade da realização deste estudo. 


\section{REFERÊNCIAS}

1. ANDREOLI, C. Effect of preharvest desiccation on yield and seed quality of soybean (Glycine max (L.) Merrill). 1977. 75 f. Dissertação (Mestrado em Fitotecnia - Produção Vegetal) - Curso de Pós-Graduação em Agronomia, North Dakota State University, Fargo, 1977.

2. ASSOCIATION OF OFFICIAL SEED ANALYSTS (AOSA). Seed vigor testing handbook. East Lansing, 1983. 93 p. (Contribuition, 32).

3. BAUR, J. R.; MILLER, F. R., BOVEY, R. W. Effects of preharvest desiccation with glyphosate on grain sorghum seed. Agronomy Journal, v. 69, p. 1015-1018, 1977.

4. BRASIL - Ministério da Agricultura e da Reforma Agrária. Regras para análise de sementes. Brasília: SNDA/ DNDV/CLAV, 1992. 365 p.

5. BRASIL - Ministério da Agricultura, Pecuária e Abastecimento. Instrução Normativa $\mathbf{n}^{\circ} \mathbf{2 5}$ de $\mathbf{1 6}$ de dezembro de 2005. Normas específicas e padrões de identidade e qualidade para produção e comercialização de sementes de algodão, arroz, aveia, azevém, feijão, girassol, mamona, milho, soja, sorgo, trevo vermelho, trigo, trigo duro, triticale e feijão caupi. Disponível em: <http://extranet.agricultura.gov.br/sislegis-consulta/consultarLegislacao.do>. Acesso em: 10 maio 2007

6. CARVALHO, N. M. et al. Aplicação em pré-colheita de dessecante em soja (Glycine max (L.) Merrill) cultivar "Viçoja", II - Efeitos imediatos sobre a germinação das sementes. Científica, v. 6, p. 209-213, 1978.

7. CARVALHO, N. M.; NAKAGAWA, J. Sementes: ciência, tecnologia e produção. 4. ed. Campinas: Fundação Cargill, 2000. $588 p$.

8. COSTA, A. V. Avaliação da qualidade fisiológica da semente de soja (Glycine max (L.) Merrill) com tegumento impermeável, produzida em três localidades do Brasil Central. 1984. 146 f. Tese (Doutorado em Fitotecnia - Produção Vegetal) - Curso de Pós-Graduação em Agronomia, Universidade Federal de Viçosa, Viçosa, MG, 1984.

9. DELOUCHE, J. C. Environmental effects on seed d evelopment and seed quality. Hortscience, v. 15, p. 775-780, 1980.

10. DURIGAN, J. C.; CARVALHO, N. M. Aplicação, em pré-colheita, de dessecantes em duas cultivares de soja (Glycine $\max$ (L.) Merrill). I - Efeitos imediatos sobre a germinação e produção de sementes. Planta Daninha, v. 3, n. 1, p. 108-115, 1980.

11. DURIGAN, J. F. Influência do tempo e das condições de estocagem sobre as propriedades químicas físico-mecânicas e nutricionais do feijão mulatinho (Phaseolus vulgaris L.). 1979. 81 f. Dissertação (Mestrado em Tecnologia de Alimentos) - Faculdade de Engenharia de Alimentos, Universidade Estadual de Campinas, Campinas, 1979.

12. EMPRESA BRASILEIRA DE PESQUISA AGROPECUÁRIA (EMBRAPA). Centro Nacional de Pesquisa da Soja. Tecnologias de produção de soja - região central do Brasil. Londrina: Embrapa Soja, 2003. 237 p.

13. EMPRESA BRASILEIRADE PESQUISAAGROPECUÁRIA (EMBRAPA). Centro Nacional de Pesquisa de Solos. Sistema brasileiro de classificação de solos. 2. ed. Rio de Janeiro: Embrapa Solos, 2006. 306 p.

14. FUNDAÇÃO-MT. Boletim de pesquisa de soja 2005. Rondonópolis, 2005. 229 p. (Boletim Técnico, 09).

15. INOUE, M. H. et al. Rendimento de grãos e qualidade de sementes de soja após a aplicação de herbicidas dessecantes. Ciência Rural, v. 33, n. 4, p. 769-770. 2003.

16. LACERDA, A. L. S. et al. Aplicação de dessecantes na cultura da soja: antecipação da colheita e produção de sementes. Planta Daninha, v. 19, n. 3, p. 381-390, 2001

17. LACERDA, A. L. S. et al. Efeitos da dessecação de plantas de soja no potencial fisiológico e sanitário das sementes. Tecnologia de Sementes, Bragantia, v. 64, n. 3, p. 447-457, 2005.

18. MAGUIRE, J. D. Speed of germination-aid in selection and evaluation for seedling emergence and vigor. Crop Science, v. 2, n. 2, p. 176-177, 1962.

19. MARCOS FILHO, J. Maturidade fisiológica de sementes de soja. Pesquisa Agropecuária Brasileira, v. 15, n. 4, p. 447-460, 1980.

20. MONSANTO. Variedades de soja Monsoy: sul e cerrado - safra. São Paulo: Monsanto, 2004. 30 p.

21. NAKASHIMA, E. K. et al. Dessecação química na obtenção de sementes de soja de elevada qualidade fisiológica. Revista Ceres, v. 47, n. 273, p. 483-493, 2000

22. RITCHIE, S. W.; HANWAY, J. J.; THOMPSON, H. E. How a soybean plant develops. Ames: lowa State University of Science and Technology Cooperative Extension Service, 1994.

23. ROCHA, V. S. et al. A qualidade da semente de soja. Viçosa, MG: UFV, 1984. 76 p.

24. ROMAN, E. S.; RODRIGUES, O.; McCRACKEN, A. Dessecação, uma tecnologia que reduz perdas na colheita de soja. Passo Fundo: Embrapa Trigo, 2001. (Comunicado Técnico, 60).

25. SMIDERLE, O. J.; CíCERO, S. M. Tratamento inseticida e qualidade de sementes de milho. Revista Brasileira de Sementes. v. 20, n. 2, p. 462-469, 1998.

26. VIEIRA, R. D. Teste de condutividade elétrica. In: VIEIRA, R. D.; CARVALHO, N. M. Testes de vigor em sementes. Jaboticabal: FUNEP/UNESP, p. 103-132, 1994.

27. WHIGHAN, D. K.; STOLLER, E. W. Soybean desiccation by paraquat, glyphosate and ametryn to acelerate harvest. Agronomy Journal, v. 71, n. 3, p. 630-633, 1979.

28. ZITO, R. K. Padrões eletroforéticos de proteínas e qualidade fisiológica durante o desenvolvimento da semente de soja. 1994. 48 f. Dissertação (Mestrado em Fitotecnia - Produção Vegetal) - Curso de Pós-Graduação em Agronomia, Universidade Federal de Viçosa, Viçosa, MG, 1994.

29. ZONTA, E. P.; MACHADO, A. A. SANEST: sistema de análise estatística para microcomputadores. Pelotas: DMEC/ IFM/UFPel, 1987.138p 